\title{
НОРМАТИВНЫЕ ВЗГЛЯДЫ НА СЕМЬЮ И ГЕНДЕР: РУССКОЯЗЫЧНЫЕ ЖИТЕЛИ ЛАТВИИ И ЭСТОНИИ В СРАВНИТЕЛЬНОЙ ПЕРСПЕКТИВЕ (ПО МАТЕРИАЛАМ ОПРОСОВ 2008 ГОДА)
}

\author{
МАРГАРИТА ФАБРИКАНТ, ВЛАДИМИР МАГУН
}

\begin{abstract}
В статье представлены результаты сравнительного исследования уровня традиционности-модерности нормативных взглядов русскоязычного населения Латвии и Эстонии на семью и гендер. Была выдвинута гипотеза, что русскоязычные занимают промежуточное положение между относительно более традиционными по своим взглядам россиянами и относительно более модерными жителями обеих стран - латышами и эстонцами. Для проверки гипотезы были использованы данные Европейского исследования иченностей, собранные в 2008 2. и включающче семь индикаторов семейно-гендерных нормативных взглядов. Полученные результаты подтвердили более сильную традиционность взглядов русскоязычного населения Латвии и Эстонии в сравнении с нерусскоязычным населением этих стран. В то же время оказалось, что значимые отличия русскоязычных жителей Латвии и Эстонии друг от друга и от россиян отсутствуют. Таким образом, все эти три группы характеризуются большей традиционностью, нежели эстонцы и латыши. Внутристрановые отличия взглядов русскоязычных жителей Латвии и Эстонии от живущих с ними в одной стране носителей латышского или эстонского языка отражают характерную для русскоязычного населения этих стран двойственную идентичность, в которой присутствует и сознание принадлежности к своей стране (Латвии или Эстонии), и одновременно сознание принадлежности к носителям русского языка и русской культуры, для которых референтной группой, трендсеттером, является Россия. Во всех пяти изученных группах более традиционные взгляды характерны для респондентов старшего возраста и состоящих в зарегистрированном браке. При этом значимого влияния уровня образования и дохода, гендерных различий, а также различий между иммигрантами в первом и втором поколениях и неиммигрантами не обнаружено.
\end{abstract}

Ключевые слова: модернизачия, социальные нормы, гендер, семья, Россия, Прибалтика.

\section{ВВЕДЕНИЕ}

Нуклеаризация семьи и изменение ее функций, фундаментальные изменения в детской смертности и рождаемости, индивидуализация образа жизни людей - все эти процессы, разворачивающиеся в России и мире в рамках демографической модернизации [Вишневский, Захаров, Иванова 2006; Вишневский 2010], связаны с появлением новых стереотипов поведения и новых социальных норм.

Изменения, которые отмечаются в качестве ключевых для характеристики второго демографического перехода, включают размывание границ социального института брака и распространение новых форм легитимного партнерства, таких как сожительство; выдвижение в центр семейной жизни отношений любви и заботы о самореализации и развитии всех членов семьи; формирование в связи с этим терпимого отношения к разводам; прогресс в сфере равноправия женщин, мужчин, представителей сексуальных меньшинств [Lesthaeghe 1995].

\footnotetext{
МАРГАРИТА САУЛОВНА ФАБРИКАНТ (mfabrykant@hse.ru), НАЦИОНАЛЬНЫЙ ИССЛЕДОВАТЕЛЬСКИЙ УНИВЕРСИТЕТ «ВЫСШАЯ ШКОЛА ЭКОНОМИКИ», РОССИЯ.

ВЛАДИМИР САМУИЛОВИч МАГУН (maghome@yandex.ru), ИНСТИТУТ СОЦИОЛОГИИ ФНИСЦ РАН, НАЦИОНАЛЬНЫЙ ИССЛЕДОВАТЕЛЬСКИЙ УНИВЕРСИТЕТ «ВЫСШАЯ ШКОЛА ЭКОНОМИКИ», РОССИЯ. 
Смысл всех этих изменений - в снятии существовавших в традиционном институте брака ограничений, в расширении возможностей личностного выбора как между различными формами организации семейной жизни, так и между семьей и другими сферами жизни, в движении к равновысокой социальной ценности и социальному достоинству всех членов общества. В более широком плане, по мнению американских исследователей А. Торнтона и Л. Янг-ДеМарко, речь идет о дальнейшем и более последовательном воплощении в жизнь выдвинутых Просвещением идеалов свободы, равенства и терпимости [Thornton, YoungDeMarco 2001]. Р. Инглхарт рассматривает демографическую модернизация как одно из направлений общего процесса модернизации и культурной эволюции [Инглхарт 2018; Borinskaya et al. 2014].

Демографическая модернизация включает и модернизацию гендерных отношений. В этой, как и в других сферах, демографическая модернизация выражается не в установлении единого эталона «эмансипированной женщины», а в легитимации свободы индивидуального выбора и конструирования гендерных ролей [Freedman 2007; Gill 2007; Kostenko, Kuzmichev, Ponarin 2016].

В разных странах мира эти процессы в целом характеризуются одинаковой направленностью [Вишневский 2011], но стартовали они в разное время и протекают с разной скоростью. В связи с этим наблюдаются различия между странами по степени приверженности людей этим новым социальным нормам. В.И. Сакевич, анализируя результаты социологического опроса, проведенного американским Pew Research Center в 2013 г. в 40 странах, обращает внимание на многомерность межстрановых различий в вопросах морали в сфере гендерно-семейных отношений. При наличии групп относительно более традиционных и более модерных стран, межстрановые различия внутри каждой из этих групп могут иметь свои особенности в зависимости от конкретного вопроса [Сакевич 2014]. В то же время показано, что нормативные представления взаимосвязаны и образуют общий фактор традиционности-модерности, куда входят показатели согласия с суждениями по широкому кругу норм гендерно-семейных отношений [Магун 2009; Фабрикант, Магун 2014].

Сравнения России с другими европейскими странами по этому обобщенному параметру позволили установить, что Россия характеризуется средневысоким показателем традиционности нормативных взглядов на семейно-гендерные отношения. Средние показатели большинства европейских стран статистически значимо отличаются от российской средней в более модерную сторону. Примечательно, что среди этих стран оказались Латвия и Эстония, в которых имеются значительные (27\% в Эстонии [Population by ethnic... 2017] и 30\% в Латвии [Latvia Population 2018]) доли русскоязычного населения. По результатам ряда исследований, русскоязычные меньшинства имеют собственные социальные идентичности [Vihalemm, Masso 2003; Ivlevs 2013; Cheskin 2015; Ehin 2016], и многим представителям этих меньшинств присуща культурная привязанность (attachment) к России. Как пишут Т. Вихалемм и А. Массо, характеризуя одну из групп своих русскоязычных респондентов в Эстонии, «их культурная и гражданская привязанности направлены к разным полюсам: гражданская - к Эстонии, а культурная - к России» («Their cultural and civic attachment is oriented towards different poles, that is the civic attachment towards Estonia and the cultural 
attachment towards Russia» [Vihalemm, Masso 2003: 110-111]). Можно предположить, что эта культурная привязанность влияет и на особенности семейно-гендерных взглядов русскоязычных меньшинств.

Исследование М.Г. Руднева посвящено базовым ценностям, а не семейно-гендерным нормативным представлениям, но оно - одно из немногих, где прямо изучалось влияние принадлежности к русскоязычному меньшинству на характеристики субъективной культуры [Руднев 2009]. В отношении русскоязычных жителей Эстонии автор показал, что их ценности, измеренные по методике Ш. Шварца, оказались ближе к ценностям российского населения, нежели к ценностям их сограждан, говорящих по-эстонски. В отношении русскоговорящих жителей Латвии картина иная: они по своим ценностям ближе к латышам, нежели к россиянам, хотя и немного меньше отличаются от россиян, чем латыши. Руднев обнаружил в Эстонии и Латвии внутристрановые различия между ценностями русскоязычных и нерусскоязычных жителей этих стран. В обеих странах русскоязычные респонденты отличались более низкими показателями ценностей открытости изменениям и более высокими показателями ценностей сохранения. Ценности сохранения предполагают большую приверженность наиболее распространенным в настоящее время взглядам, ценности же открытости - наоборот, большую готовность к изменениям, инновационность. Можно предположить, что эти ценности проявляются и в сфере семейно-гендерных норм, и поэтому русскоязычное население Эстонии и Латвии будет привержено более традиционным нормам, нежели живущие в тех же странах эстонцы и латыши.

Цель настоящего исследования - изучить влияние принадлежности к русскоязычному меньшинству на нормативные взгляды жителей Эстонии и Латвии. Ранее было выявлено, что средние показатели Латвии и Эстонии указывают на их большую модерность и меньшую традиционность по сравнению с россиянами. Учитывая, что русскоязычное население Латвии и Эстонии находится под влиянием взглядов на семью и гендер, которые распространены в России, но в то же время испытывают воздействие и тех взглядов, которые распространены в их собственных странах, мы предполагаем, что русскоязычное население будет придерживаться более традиционных представлений в семейно-гендерной сфере, чем латыши и эстонцы, но при этом более модерных, чем россияне.

\section{ДАННЫЕ И МЕТОДОЛОГИЯ}

Для проверки выдвинутой гипотезы были использованы данные 5-ой волны Европейского исследования ценностей (European Values Study, далее - EVS), собранные в 2008 г. Европейское исследование ценностей проводится на репрезентативных страновых выборках. Нами были использованы данные для выборок по России, а также Латвии и Эстонии - двух стран с существенной долей русскоязычного населения. Объем российской выборки - 1504, латвийской и эстонской - 1506 и 1518 респондентов соответственно. Принадлежность респондентов двух прибалтийских стран к русскоязычным определяли на основании переменной «язык, на котором проводилось интервью с респондентом», включенной в базу данных. На этом основании эстонская выборка была разделена на 469 русскоязычных и 1049 использовавших эстонский язык, а латвийская - на 531 русскоязычных и 975 использовавших 
латышский язык. Всем российским респондентам предлагали опросник на русском языке. В дальнейшем респонденты из российской выборки будут обозначаться как россияне, респонденты из Латвии и Эстонии, выбравшие русскоязычную версию опросника, - как русскоязычные в Латвии и Эстонии, а жители Латвии и Эстонии, проходившие опрос на государственных языках своих стран, - соответственно, как латыши и эстонцы.

В качестве зависимых переменных для исследования были отобраны 7 показателей, характеризующих представления людей о гендерных и семейных нормах. Большинство этих норм четко сфокусировано на горизонтальных отношениях между партнерами либо на вертикальных отношениях между родителями и детьми, но для описания нескольких норм потребовались дополнительные признаки. По каждой норме одни варианты ответа соответствуют более традиционным, консервативным взглядам, а другие, напротив, более модерным, либеральным. Шкалы для ответов об отношении респондентов к разным нормам не совпадали по числу градаций. Для удобства обработки и интерпретации данных числовые обозначения по всем этим шкалам переменных были перекодированы таким образом, чтобы меньшим значениям соответствовала более традиционная нормативная ориентация, а большим - более модерная.

Перечислим 3 переменные, характеризующие взгляды людей на горизонтальные отношения.

Переменная, которая в базе данных EVS указана под номером v150, соответствует вопросу анкеты: «Согласны Bы или нет со следуюшим утверждением: "Брак - это устаревший способ организации семьи”?» Варианты ответа: «1 - Не согласен. 2 - Согласен», согласие с утверждением, что брак устарел, соответствует более модерным нормам, несогласие - более консервативным.

Переменная $v 153$ в анкете соответствует вопросу: «Насколько Bы согласны или не согласны со следующим утверждением: Брак или длительные постоянные отношения необходимы, чтобы быть счастливым». Варианты ответа: «1 - Полностью согласен. 2 Согласен. 3 - Ни то, ни другое. 4 - Не согласен. 5 - Полностью не согласен». Согласие с утверждением о необходимости постоянных отношений соответствует более традиционным нормам, несогласие - более модерным.

Переменная v155 соответствует вопросу: «Насколько Вы согласны или не согласны со следуюшим утверждением: Я считаю нормальным совместное проживание без заключения брака». Варианты ответа: «1 - Полностью не согласен. 2 - Не согласен. 3 - Ни то, ни другое. 4 - Согласен. 5 - Полностью согласен». Согласие с приемлемостью внебрачного сожительства соответствует более модерным нормам, несогласие - более традиционным.

Еще 3 переменные характеризуют взгляды людей на вертикальные отношения между родителями и детьми.

Переменная v149 соответствует вопросу: «Как Bbl считаете, необходимо ли женщине для того, чтобы чувствовать себя полноценной, иметь детей или это не обязательно?» Варианты ответа: «1 - Необходимо иметь детей. 2 - Не обязательно». Согласие с 
необходимостью для женщины иметь детей соответствует более традиционным нормам, несогласие - более модерным ${ }^{1}$.

Переменная v151 соответствует вопросу: «Если женщина хочет иметь ребенка, не желая при этом устанавливать прочные отношения с мужчиной, одобряете Вы это или нет?» Варианты ответа: «1 - Не одобряю. 2 - Смотря по обстоятельствам. 3 - Одобряю». Одобрение желания женщины стать «матерью-одиночкой» соответствует более модерным нормам, неодобрение - более традиционным.

Следующая переменная v154 отражает отношение к норме, которая находится в процессе формирования, толерантность к социальным явлениям, которые регулируются посредством этой нормы, возникла относительно недавно, и поэтому она представляет собой своего рода «передний край» модернизации. Речь идет о праве гомосексуальной пары иметь детей, и в этой норме присутствует двойная непривычность для респондентов: новизна проявляется прежде всего в допустимости самого существования гомосексуальной пары и уже дополнительно к этому - в допустимости для нее усыновлять ребенка (т.е. здесь имеет место комбинация двух видов нетрадиционных отношений: и по горизонтали, и по вертикали). В анкете вопрос звучал так: «Насколько Bbl согласны или не согласны со следуюшим утверждением: Гомосексуальные пары должны иметь возможность усыновлять детей». Варианты ответа: «1 - Полностью не согласен. 2 - Не согласен. 3 - Ни то, ни другое. 4 Согласен. 5 - Полностью согласен». Согласие с правом на усыновление для гомосексуальных пар соответствует более модерным ценностям, несогласие - более традиционным.

Еще один показатель касается взглядов людей на соотношение семейных и трудовых ролей в жизни женщины. В традиционной системе взглядов в качестве приоритетных или даже единственно возможных для женщины рассматривались роли жены и матери, а мужчине отводилась роль добытчика, модернизация же выражается в отказе от гендерной асимметрии в распределении ролей. Переменная $v 161$ отражает эти изменения и соответствующий вопрос звучит так: «Насколько Вы согласны или не согласны со следующим утверждением: Работаэто хорошо, но в действительности, большинство женщин хотят иметь дом и детей». Варианты ответа: «1 - Полностью согласен. 2 - Согласен. 3 - Не согласен. 4 - Полностью не согласен». Согласие с утверждением, что дом и дети, а не работа, - подлинная потребность женщины, соответствует более традиционным ценностям, а несогласие - более модерным.

Анализ этих данных был проведен в два этапа. На первом (описательном) этапе были построены частотные распределения по каждой переменной внутри каждой из пяти выборок: русскоязычных в Латвии, русскоязычных в Эстонии, латышей, эстонцев и россиян. Далее все семь описанных выше переменных были подвергнуты факторному анализу методом главных осей (без вращения), таким образом была построена новая переменная, отражающая обобщенную традиционность-модерность нормативных взглядов на семью и гендер и проведено сравнение средних значений этой переменной в разных страноязыковых группах. На втором (объяснительном) этапе влияние страноязыковой принадлежности респондентов на

${ }^{1}$ В Европейском исследовании ценностей присутствует аналогичный вопрос о необходимости иметь детей мужчине. Его включению в анализ помешали ошибки перевода в анкетах, предназначенных для части выборочных совокупностей. 
традиционность-модерность их нормативных взглядов оценивали с помощью моделей линейного регрессионного анализа, в которых, наряду с фактором страноязыковой принадлежности, участвовали контрольные социально-демографические переменные. К ним относятся: пол (мужской или женский); возраст (число полных лет, вычислено по дате рождения респондента; медианный возраст респондентов составил 47 лет при минимальном значении 18 лет, максимальном - 98 лет); наличие высшего образования; матримониальный статус (состоит в зарегистрированном браке и живет вместе с супругом/супругой - не состоит в браке и/или не живет вместе с супругом/супругой); число детей у респондента (количественная переменная); размер населенного пункта (пятибалльная шкала: 1 - меньше 5 тыс. человек, 2 - 5-20 тыс., 3 - 20-100 тыс., 4 - 100-500 тыс., 5 - от 500 тыс.); являются ли респондент, его отец или мать иммигрантами (три отдельные дихотомические переменные); уровень среднемесячного дохода домохозяйства, к которому принадлежит респондент (доход в каждой стране измерялся в ее денежных единицах, весь внутристрановой диапазон доходов был разделен на 15 интервалов, и респондент выбирал интервал, к которому принадлежит, в международном массиве эти оценки перекодировались в трехбалльную шкалу «низкий средний - высокий»).

\section{РЕЗУЛЬТАТЫ И ИХ ОБСУЖДЕНИЕ}

\section{Описательные характеристики показателей традиционности- модерности семейно-гендерных нормативных взглядов}

На первом этапе анализа рассмотрим распределения нормативных взглядов в каждой из пяти страноязыковых групп, в графической форме они представлены на рисунках 1-7, на каждом рисунке выборки расположены слева направо в порядке от наибольшей традиционности нормативных представлений к наименьшей традиционности или большей модерности.

На рисунке 1 приводятся распределения реакций респондентов на суждение «Брак это устаревший способ организации семьи», согласие с этим утверждением отражает более модерные, а несогласие - более традиционные представления. Различия между распределениями в данном случае очень малы и статистически незначимы, около 80\% респондентов во всех пяти выборках не согласны с тем, что институт брака устарел. Таким образом, большинство населения во всех рассматриваемых совокупностях рассматривает институт брака как необходимый элемент общественной организации.

Следующее тестируемое утверждение - «Брак или длительные постоянные отношения необходимы, чтобы быть счастливым». В нем упомянутый в предыдущем суждении институт брака дополнен вариантом «длительных постоянных отношений», которые могут существовать и без официального оформления брака. Изменена также модальность нормативного высказывания с негативной («устарел») на позитивную («чтобы быть счастливым»). Кроме того, респондентам предлагается более дробная шкала (пятибалльная вместо двухбалльной). Все эти изменения не слишком изменили порядок цифр, характеризовавших рассмотренную выше нормативную приверженность официальному браку: в разных выборках сумма ответов «согласен» и «полностью согласен» колеблется от 69 
до $82 \%$. Это означает, что большинство респондентов рассматривают институты официального брака или длительного неофициального партнерства как универсальную социальную норму.

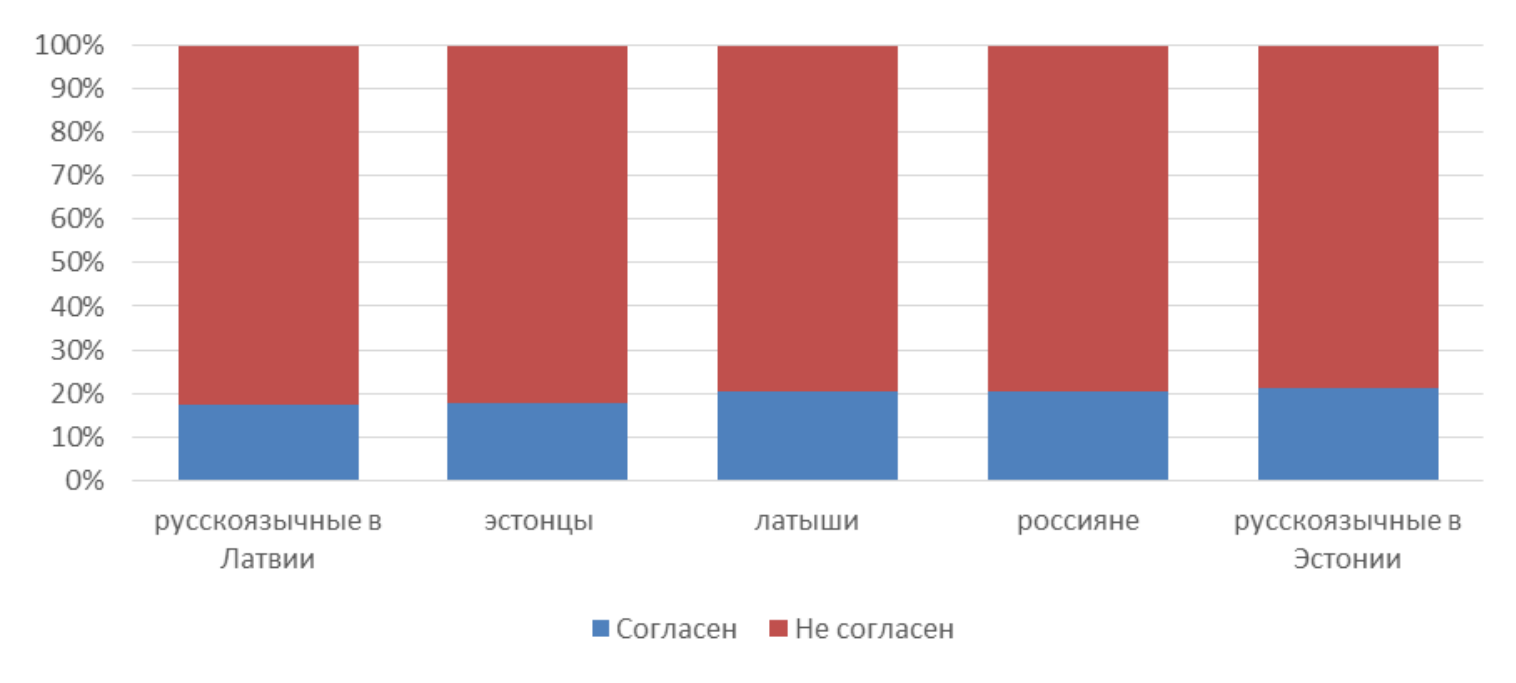

\section{Рисунок 1. Реакции на суждение «Брак - это устаревший способ организации семьи» в пяти страноязыковых группах}

Вместе с тем реакции респондентов на данное суждение оказались более чувствительны к страноязыковым различиям. По суммарной доле согласных плюс полностью согласных рассматриваемые группы делятся на две категории: более традиционно настроенные россияне и русскоязычные жители Латвии и Эстонии, с одной стороны, и менее традиционно настроенные латыши и эстонцы.

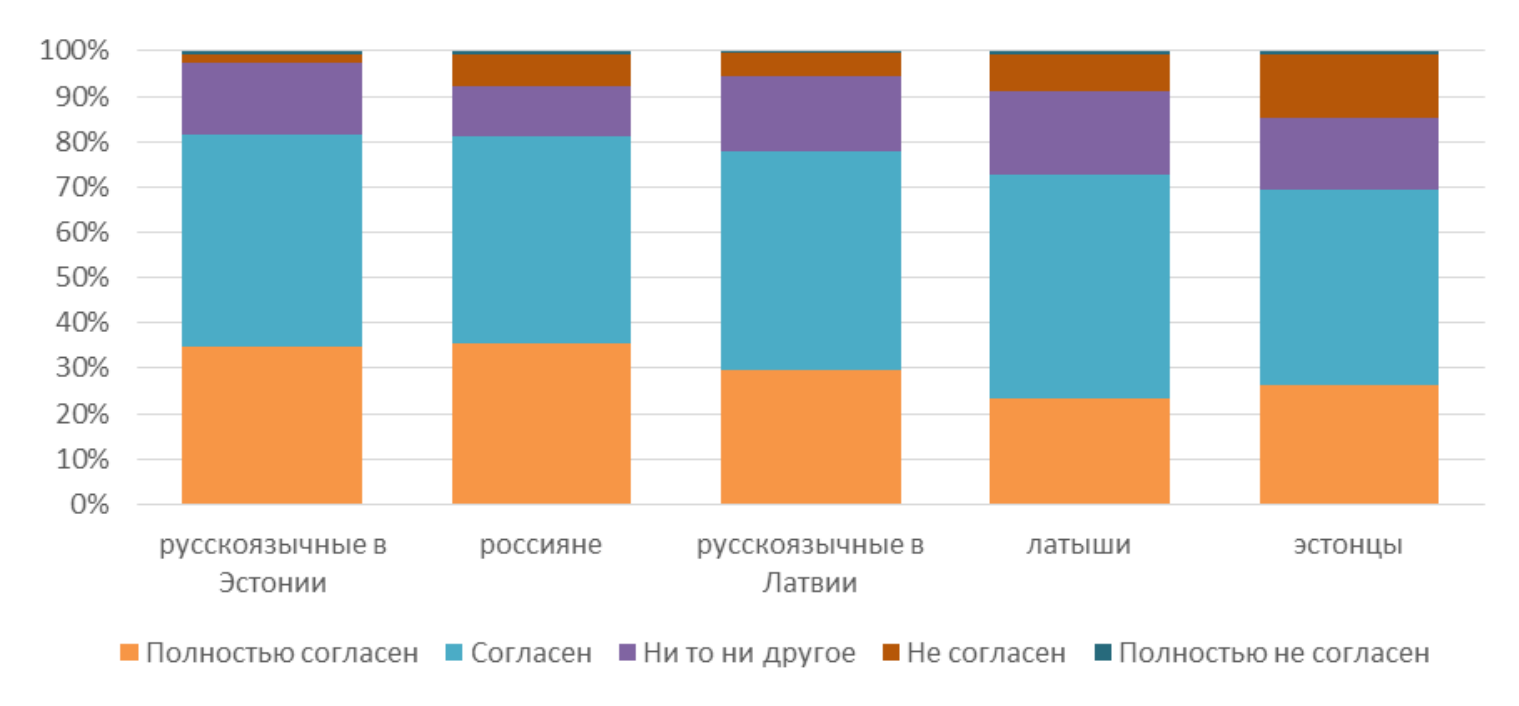

Рисунок 2. Реакции на суждение «Брак или длительные постоянные отношения необходимы, чтобы быть счастливым» в пяти страноязыковых группах

Рисунок 3 отражает реакции респондентов на утверждение о допустимости сожительств. Здесь преобладают модерные нормативные представления: от 59 до 80\% респондентов в каждой выборке согласны либо полностью согласны с допустимостью 
сожительства без официальной регистрации брака. Эта информация дополняет картину нормативных взглядов на разные формы отношений между партнерами. Реакции на два предшествующих вопроса указывают на то, что респонденты считают брак или длительное совместное проживание социальной нормой, теперь же мы видим, что респонденты «разрешают» и отклонение от этой нормы. Они считают нормальным совместное проживание без заключения брака, причем не обязательно длительное, правда не всегда связывают такую форму отношений с ощущениями счастья. Наибольшее согласие с «нормальностью» сожительств выражают эстонцы и латыши (их доли согласия значимо не различаются), наименьшее согласие - россияне. Русскоязычные в Латвии и Эстонии занимают по степени согласия промежуточную позицию, значимо отличаясь от россиян и эстонцев и незначимо от латышей.

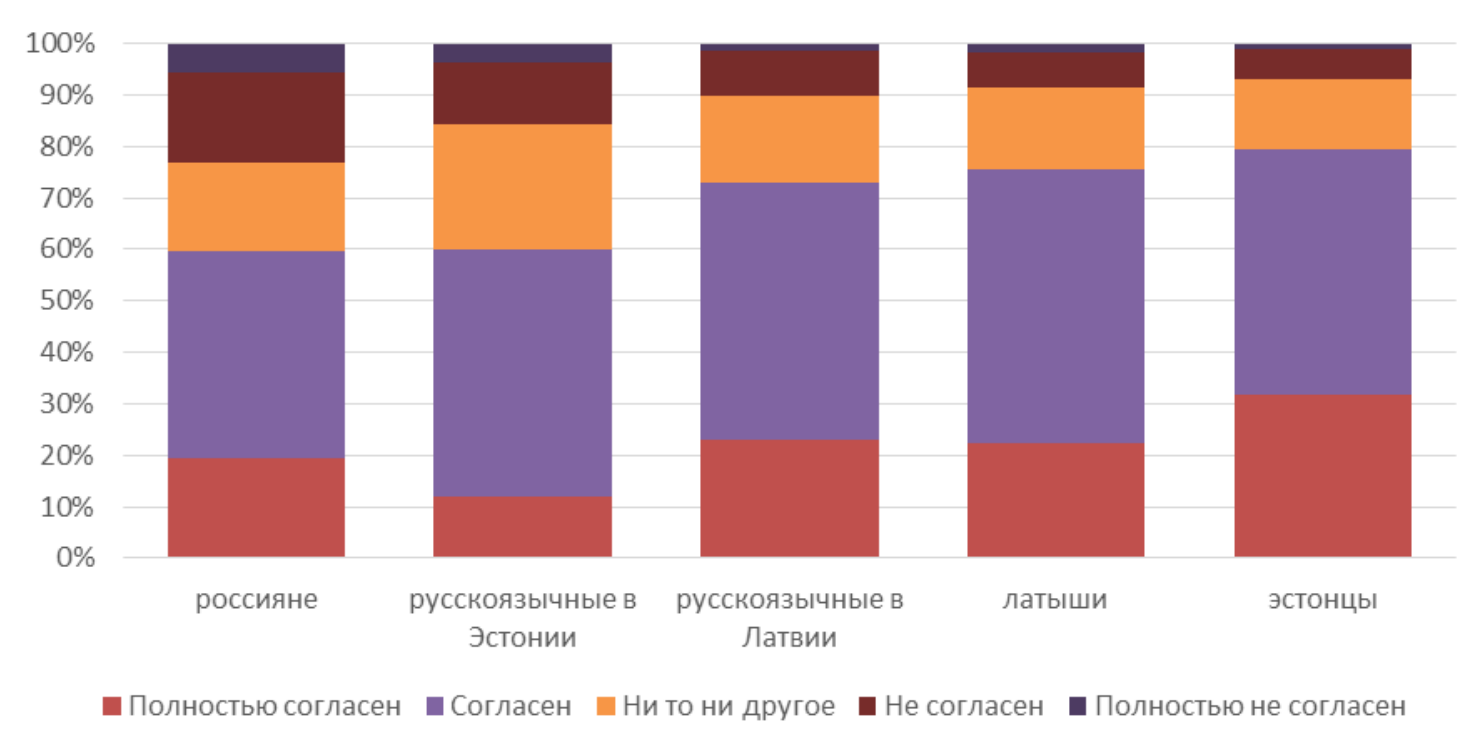

\section{Рисунок 3. Реакции на суждение «Я считаю нормальным совместное проживание без заключения брака» в пяти страноязыковых группах}

На рисунке 4 представлены распределения позиций респондентов в отношении необходимости для женщины иметь детей. Здесь сильно преобладают традиционные взгляды, не менее двух третей респондентов в каждой выборке считают, что для ощущения собственной полноценности женщине необходимо иметь детей. Россияне и русскоязычные в Латвии и Эстонии (не различающиеся между собой) чаще всего оказываются носителями традиционных представлений. Реже всего (в 67\% случаев) такие взгляды выражают эстонцы; латыши занимают в этом отношении промежуточное положение, но их показатель ближе к показателям россиян и русскоязычных. 


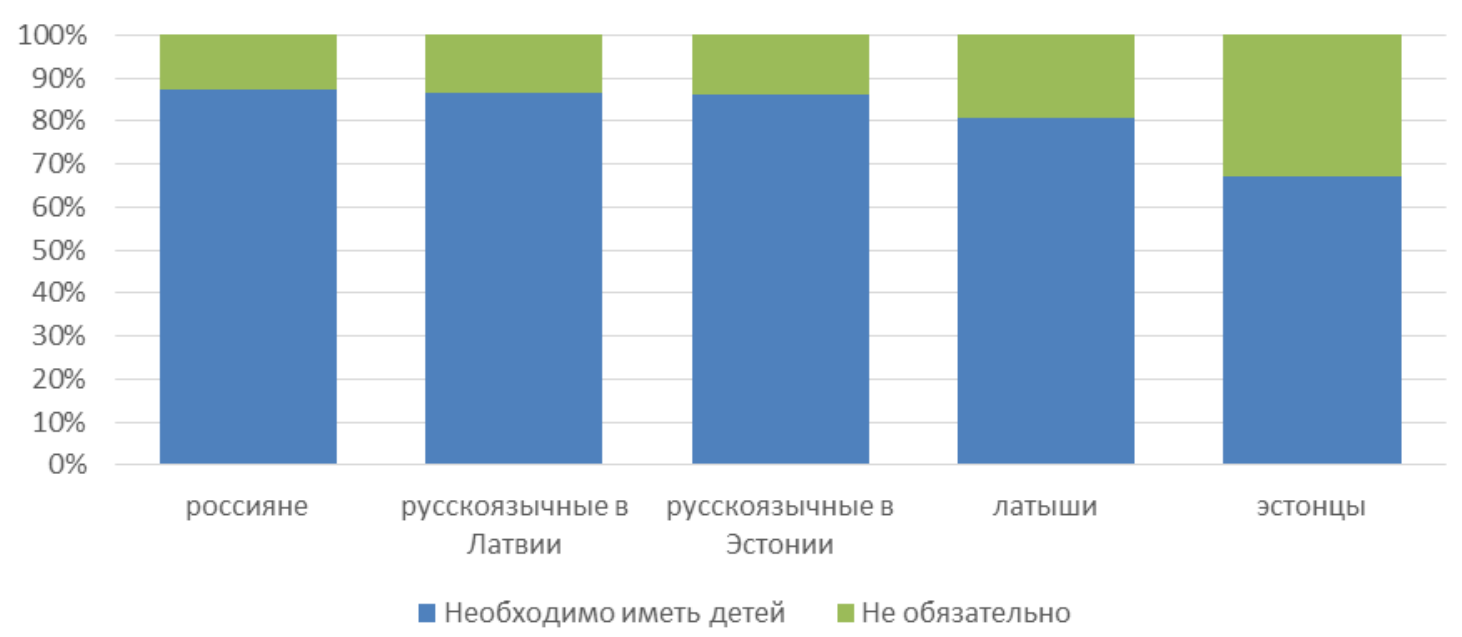

Рисунок 4. Ответы на вопрос «Необходимо ли женщине для того, чтобы чувствовать себя полноценной, иметь детей или это не обязательно?» в пяти страноязыковых группах

На рисунке 5 представлены позиции респондентов в отношении матерей, желающих иметь ребенка, не устанавливая прочных отношений с мужчиной (тех, кто реализовал такое желание, обычно называют у нас «матерями-одиночками»). От 45 до 63\% респондентов одобряют подобное желание женщины. Плюс еще некоторая часть респондентов занимает относительно толерантную позицию «смотря по обстоятельствам», и таким образом, во всех выборках большинство респондентов придерживаются в этом отношении модерных нормативных взглядов. Наименьшая доля одобрения (суммарно - безусловного и условного) - у русскоязычных в Эстонии и Латвии, а наибольшее одобрение такого желания женщины у латышей. В Латвии наблюдается контраст нормативных позиций между говорящими на латышском и русском языке.

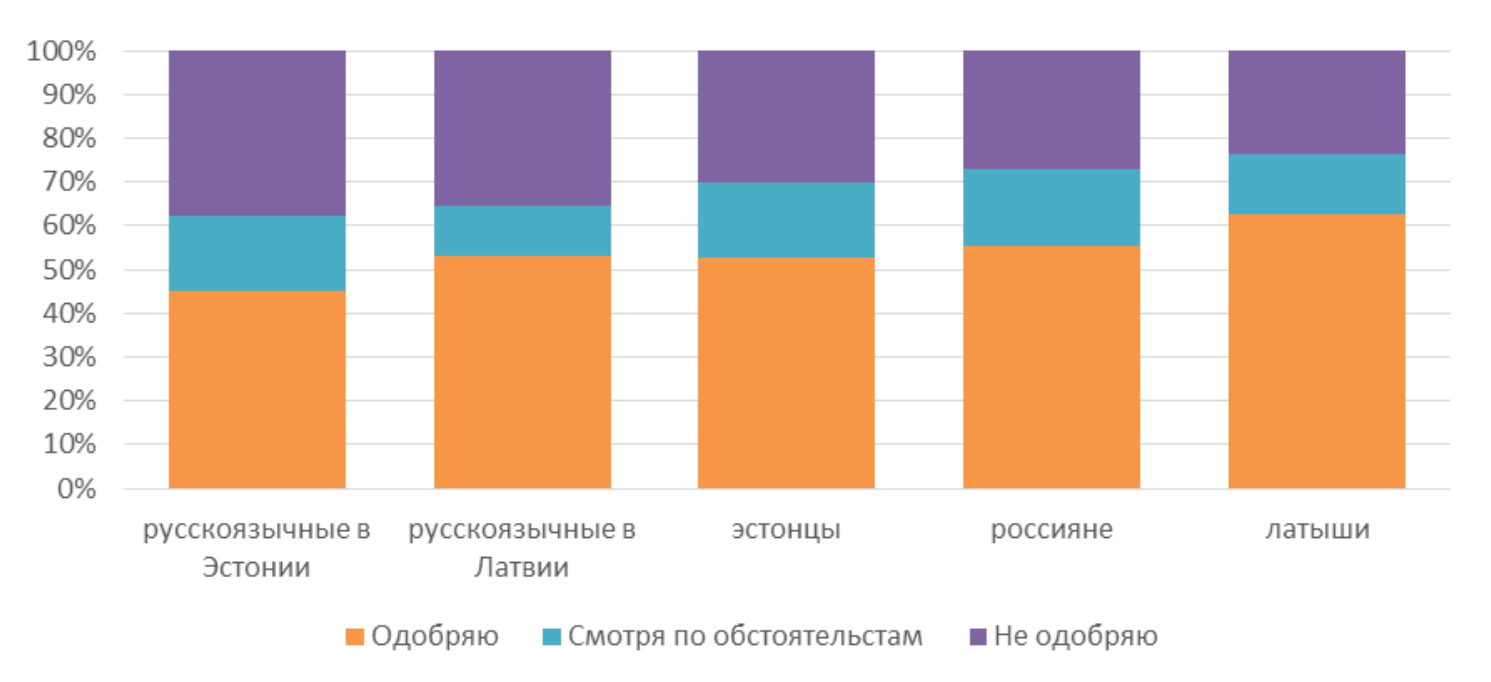

Рисунок 5. Ответы на вопрос «Если женщина хочет иметь ребенка, не желая при этом устанавливать прочные отношения с мужчиной, одобряете Вы это или нет?» в пяти страноязыковых группах 
На рисунке 6 представлены позиции респондентов в отношении права гомосексуальных пар на усыновление. Здесь, что неудивительно для столь радикальной новации, во всех пяти выборках явно преобладают традиционные взгляды, от 68 до 75\% респондентов не согласны или полностью не согласны на предоставление подобного права. Небольшие, но значимые отличия имеются между чуть менее толерантными в этом отношении латышами, с одной стороны, и чуть более толерантными эстонскими и российскими респондентами - с другой. Внутри каждой из этих двух категорий, группы между собой не отличаются.

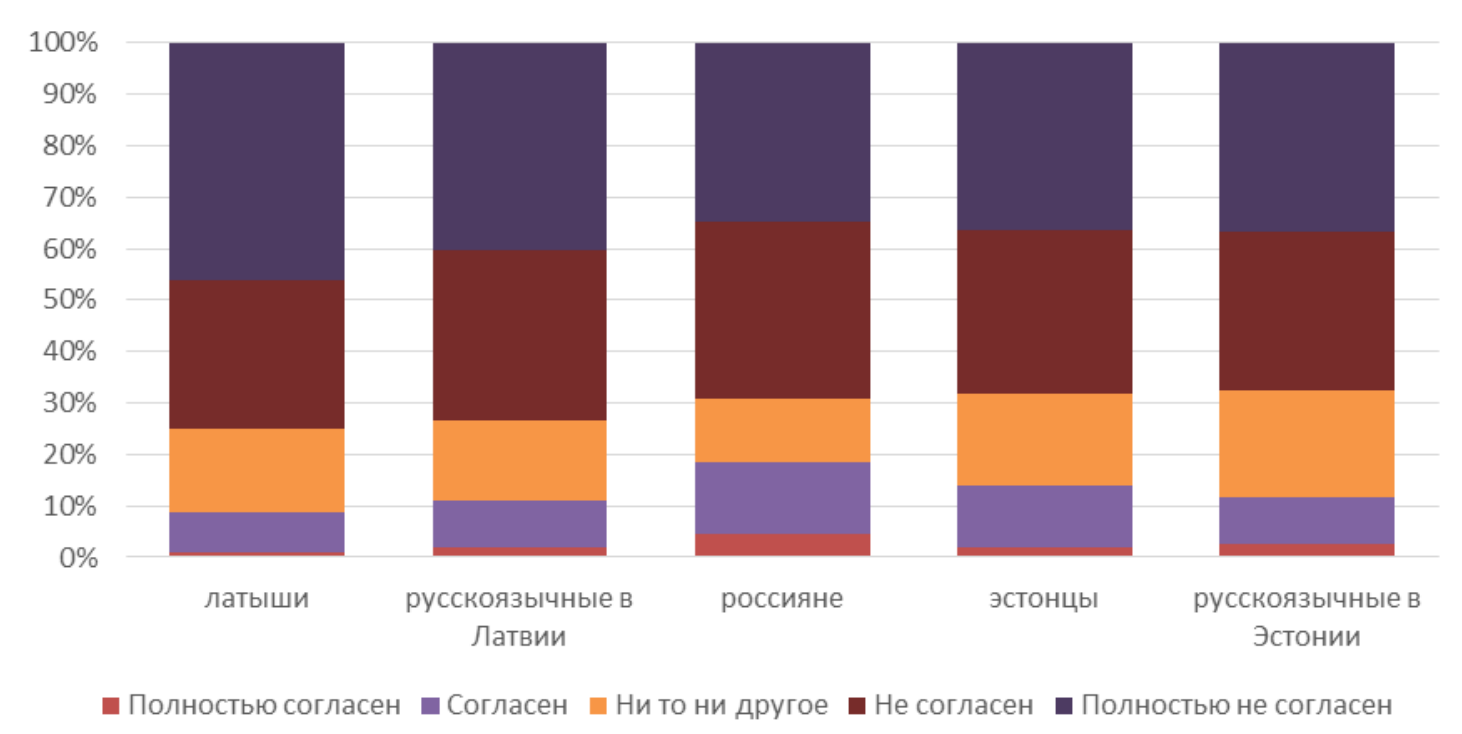

\section{Рисунок 6. Реакции на суждение «Гомосексуальные пары должны иметь возможность усыновлять детей» в пяти страноязыковых группах}

На рисунке 7 отражены позиции респондентов в отношении социальной нормы, утверждающей приоритет семейной роли женщины. В отношении этой радикально традиционалистской нормы, которая к тому же апеллирует к якобы «действительным» желаниям женщины, во всех пяти выборках преобладает согласие. Совокупная доля согласных и полностью согласных немного превышает половину выборки (56 и 61\%) среди латышей и эстонцев, приближается к $90 \%$ у россиян и русскоязычных в Эстонии, и равняется $72 \%$ у русскоязычных в Латвии (различия между этими тремя категориями значимы). Таким образом, наиболее традиционалистских позиций придерживаются русскоязычные в Эстонии и россияне, латыши и эстонцы выражают с этими позициями наименьшее согласие (внутри упомянутых пар нет значимых различий), а русскоязычные в Латвии занимают в этом отношении промежуточное положение, отличаясь значимо от обоих «полюсов». 


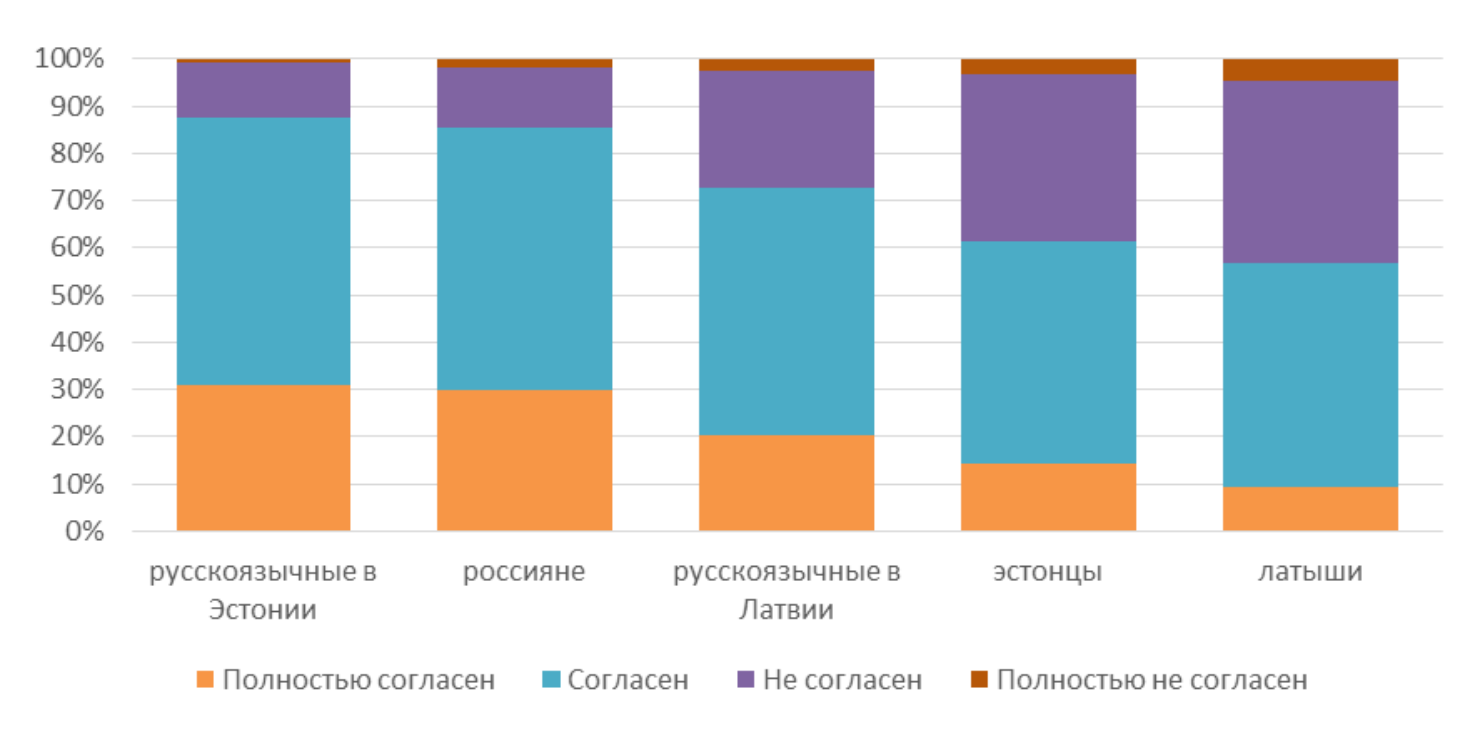

\section{Рисунок 7. Реакции на суждение «Работа - это хорошо, но в действительности большинство женщин хотят иметь дом и детей» в пяти страноязыковых группах}

Таким образом, в отношении большинства рассмотренных семейно-гендерных норм респонденты во всех страноязыковых группах склоняются в сторону традиционных взглядов. По степени традиционности (или традиционности-модерности) этих взглядов между страноязыковыми группами наблюдаются статистически значимые различия, в том числе и различия между русскоязычными в Эстонии и эстонцами, а также между русскоязычными в Латвии и латышами.

Чтобы получить обобщенный параметр, характеризующий традиционностьмодерность нормативных представлений респондентов, все 8 переменных, описывающих отдельные аспекты взглядов на семейно-гендерные проблемы, были подвергнуты факторному анализу. Матрица факторных нагрузок, выявленная на всем массиве, а также аналогичные матрицы, полученные на каждой из пяти страноязыковых выборок, содержали близкий по смыслу и по структуре нагрузок фактор, в который с положительными нагрузками вошли все рассматриваемые переменные (таблица 1). Шкалы переменных преобразованы так, что большие по величине оценки указывают на меньшую традиционность или большую модерность нормативных взглядов, соответственно переформулированы и названия признаков.

Таким образом, этот фактор (он первый по порядку и наибольший по доле описываемой дисперсии во всех шести факторных матрицах) и представляет собой искомый обобщенный параметр традиционности-модерности нормативных взглядов, похожий на тот, что описан в литературе [Магун 2009; Фабрикант, Магун 2014]. Хотя заметные положительные нагрузки по данному фактору имеют показатели согласия со всеми рассматриваемыми в исследовании взглядами, величины разных показателей неодинаковы. Наиболее тесно в большинстве групп связаны с фактором взгляды относительно необходимости постоянных отношений и допустимости сожительства, иными словами, в центре этого фактора - взгляды на формат горизонтальных отношений между партнерами. 


\section{Таблица 1. Фактор традиционности-модерности нормативных взглядов на семью и гендер на всем массиве и в пяти страноязыковых группах (метод главных осей)}

\begin{tabular}{|c|c|c|c|c|c|c|}
\hline \multirow[b]{2}{*}{ Названия переменных } & \multicolumn{6}{|c|}{ Факторные нагрузки } \\
\hline & $\begin{array}{c}\text { Весь } \\
\text { массив } \\
\mathrm{N}=3511\end{array}$ & $\begin{array}{c}\text { Русско- } \\
\text { язычные } \\
\text { в Латвии } \\
\text { N= } 409\end{array}$ & $\begin{array}{c}\text { Русско- } \\
\text { язычные } \\
\text { в Эстонии } \\
\text { N=403 }\end{array}$ & $\begin{array}{l}\text { Латыши } \\
\mathrm{N}=758\end{array}$ & $\begin{array}{c}\text { Эстонцы } \\
\mathrm{N}=878\end{array}$ & $\begin{array}{c}\text { Россияне } \\
\mathrm{N}=1063\end{array}$ \\
\hline $\begin{array}{l}\text { Нет необходимости в } \\
\text { отношениях (v154) }\end{array}$ & 0,60 & 0,38 & 0,59 & 0,68 & 0,59 & 0,37 \\
\hline Допустимость сожительства (v156) & 0,51 & 0,29 & 0,59 & 0,52 & 0,51 & 0,71 \\
\hline $\begin{array}{l}\text { Нет необходимости в детях для } \\
\text { женщины (v149) }\end{array}$ & 0,44 & 0,49 & 0,46 & 0,45 & 0,54 & 0,21 \\
\hline $\begin{array}{l}\text { Допустимость матерей-одиночек } \\
\text { (v152) }\end{array}$ & 0,40 & 0,37 & 0,42 & 0,34 & 0,44 & 0,46 \\
\hline Институт брака устарел (v150) & 0,32 & 0,48 & 0,47 & 0,44 & 0,27 & 0,32 \\
\hline $\begin{array}{l}\text { Неверно, что большинство женщин } \\
\text { хотят дом и детей (v161) }\end{array}$ & 0,28 & 0,18 & 0,38 & 0,15 & 0,24 & 0,19 \\
\hline $\begin{array}{l}\text { Право гомосексуальных пар на } \\
\text { усыновление (v155) }\end{array}$ & 0,21 & 0,19 & 0,32 & 0,21 & 0,33 & 0,17 \\
\hline Процент объясненной дисперсии & 17,1 & 13,0 & 22,2 & 18,6 & 19,1 & 15,3 \\
\hline
\end{tabular}

Примечание: Отсортировано по величине факторных нагрузок на всем массиве.

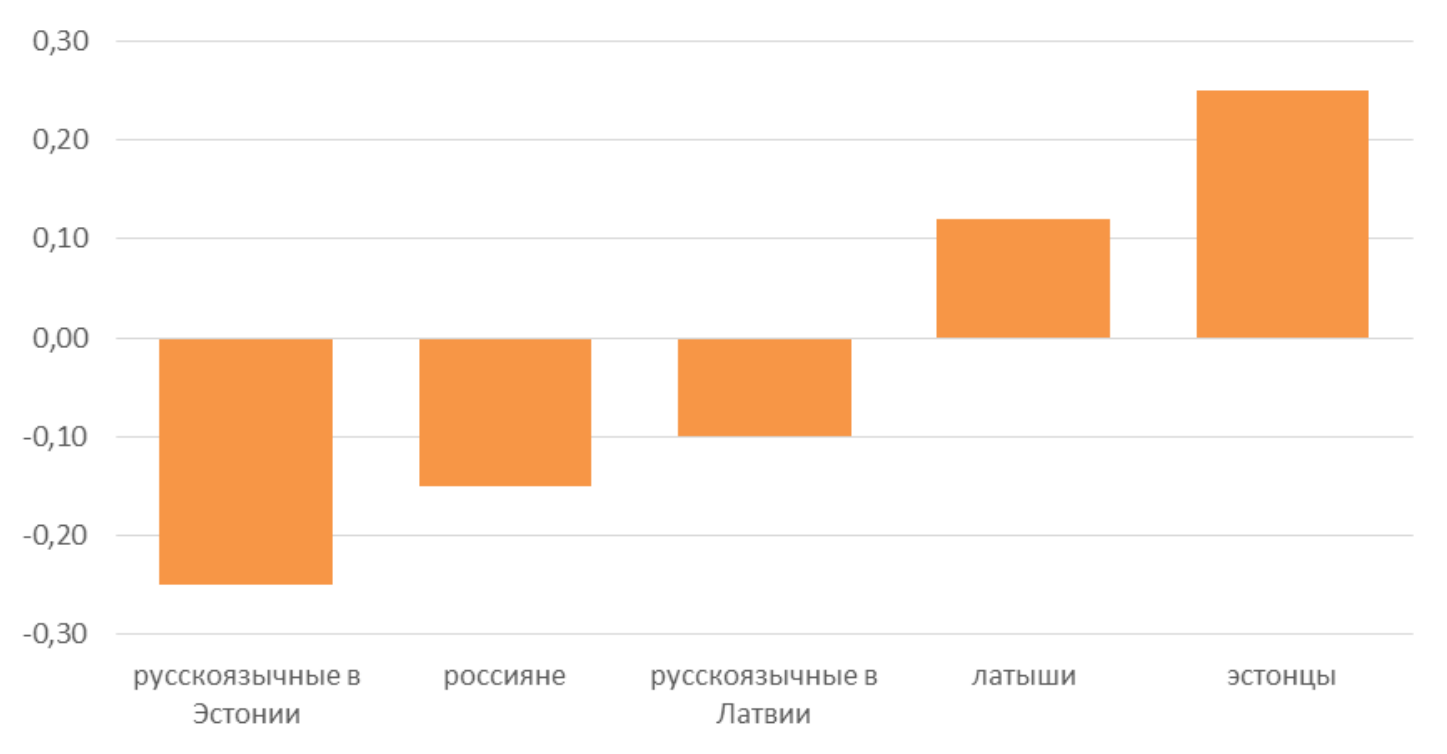

Рисунок 8. Средние значения фактора традиционности-модерности нормативных взглядов в пяти страноязыковых группах

Рисунок 8 демонстрирует различия средних значений обобщенного фактора традиционности-модерности в пяти рассматриваемых страноязыковых группах, различия статистически значимы $(p<0,001)$ между всеми группами, кроме различий между русскоязычными в Латвии и россиянами. Как видим, россияне, а также русскоязычные респонденты в Эстонии и Латвии демонстрируют большую традиционность или меньшую модерность, чем латыши и эстонцы. В этих различиях смешаны эффекты собственно страноязыковой принадлежности и социально-демографического состава этих групп. Чтобы отделить влияние страноязыковой принадлежности на уровень общей традиционности- 
модерности нормативных взглядов от влияний социально-демографического состава рассматриваемых страноязыковых групп, были построены регрессионные модели.

\section{Влияние страноязыковой принадлежности респондентов на традиционность-модерность их нормативных взглядов: регрессионный анализ}

Во всех регрессионных моделях зависимая переменная - общий фактор традиционностимодерности, большие значения которого соответствуют меньшей традиционности или большей модерности семейно-гендерных нормативных взглядов, а меньшие - их большей традиционности или меньшей модерности.

Основная независимая переменная - принадлежность респондента к одной из пяти страноязыковых групп; для оценки ее эффектов были сконструированы 5 фиктивных дихотомических переменных, фиксирующих, относится ли респондент к соответствующей группе или нет. Чтобы попарно сравнить все группы между собой, мы построили пять регрессионных моделей, меняя каждый раз референтную группу. В качестве контрольных переменных в модели были также включены социально-демографические характеристики респондентов, их эффекты для всех пяти моделей одинаковы.

Результаты расчетов приведены в таблице 2. Положительные регрессионные коэффициенты означают для количественных независимых переменных положительную связь с модерностью представлений, а для качественных переменных - относительно большую модерность представлений для соответствующей группы респондентов в сравнении с референтной.

Регрессионные коэффициенты показывают, что все различия между россиянами и русскоязычными группами являются статистически незначимыми, а все отличия этих групп от латышей и эстонцев, как и различия между двумя последними, статистически значимы. Эстонцы оказываются менее приверженными традиционным взглядам, чем латыши, но обе эти группы настроены менее традиционно (или более модерно), чем россияне и русскоязычные респонденты. При этом отличия русскоязычных от остального населения своих стран (в сторону большей традиционности) в Эстонии более заметны, чем в Латвии.

Что касается социально-демографических предикторов, для массива в целом выявлены значимые эффекты для возраста, матримониального статуса, числа детей и размера населенного пункта, в котором проживает респондент. Большей традиционностью взглядов, как и следовало ожидать, отличаются респонденты более старшего возраста, респонденты, состоящие в традиционном официально зарегистрированном браке и живущие совместно с супругом/супругой, имеющие большее число детей и проживающие в наименьшем по размеру населенном пункте (в сравнении с несколько более крупными по размеру поселениями).

Вопреки возможному предположению о позитивной связи между уровнем дохода и модерностью взглядов (те, кто в большей степени выиграл от модернизации, предположительно должны придерживаться более модерных взглядов во всех сферах, в том числе и в семейно-гендерной) значимого эффекта для этой переменной не наблюдается. Это может быть результатом двух противоположно направленных и уравновешивающих друг 
друга механизмов: эффект меньшего выигрыша от модернизации у респондентов с более низким уровнем дохода может нейтрализоваться тем, что для реализации традиционалистской семейно-гендерной жизненной модели ее стороннику необходимы довольно значительные ресурсы на содержание детей или неработающей супруги (если речь о мужчине), и лица с низким доходом просто адаптируют свои взгляды к своей реальной финансовой ситуации (см. [Rivera, Tilcsik 2016]).

Примечательно, что в данном массиве на уровень традиционности-модерности семейно-гендерных нормативных представлений не влияют ни пол респондента, ни наличие у него высшего образования. Дополнительно нами был проверен эффект наличия высшего образования родителей, и этот эффект также оказался незначимым. Это объясняется достаточно сильной отрицательной корреляцией наличия высшего образования с возрастом и отрицательной же связью с возрастом респондента уровня образования его родителей. При исключении из числа независимых переменных возраста эффект высшего образования становится статистически значимым, а направление, как и следовало ожидать, положительным: люди с высшим образованием склонны придерживаться более модерных нормативных представлений. Включение более дробной международной шкалы образования ISCED дало те же результаты, что и дихотомия наличие-отсутствие высшего образования.

Не влияет значимо и то, является ли респондент иммигрантом в первом или во втором поколении (о втором поколении иммигрантов мы делаем вывод на основании информации об иммигрантском статусе родителей). Поскольку в подвыборках россиян, а также латышей и эстонцев число иммигрантов в первом поколении крайне мало, а в обеих подвыборках русскоязычных, напротив, значительно (почти 40\% русскоязычных в Латвии и почти 50\% русскоязычных в Эстонии), мы дополнительно проверили влияние этой переменной для каждой из подвыборок русскоязычных, однако и внутри обеих подвыборок значимого эффекта обнаружено не было. Для основной части иммигрантов среди русскоязычных в Латвии и Эстонии страной рождения является Россия (на втором и третьем местах с большим отрывом - Белоруссия и Украина, другие страны, тоже постсоветские, встречаются в единичных случаях), и отсутствие регрессионного эффекта иммиграции указывает на то, что традиционализм нормативных взглядов, скорее всего, не «привезен» этими людьми из России, а сформирован в странах нынешнего проживания. 
Таблица 2. Влияние страноязыковой принадлежности и социально-демографических переменных на общий уровень традиционности-модерности: модели линейной регрессии со стандартизованными коэффициентами

\begin{tabular}{|c|c|c|c|c|c|}
\hline & $\begin{array}{c}\text { Референтная группа } \\
\text { - русскоязычные в } \\
\text { Латвии } \\
\end{array}$ & $\begin{array}{c}\text { Референтная группа } \\
\text { - русскоязычные в } \\
\text { Эстонии } \\
\end{array}$ & $\begin{array}{c}\text { Референтная группа } \\
\text { - латыши } \\
\end{array}$ & $\begin{array}{c}\text { Референтная группа } \\
\text { - эстонцы }\end{array}$ & $\begin{array}{c}\text { Референтная группа } \\
\text { - россияне }\end{array}$ \\
\hline \multicolumn{6}{|c|}{ Основная независимая переменная } \\
\hline \multicolumn{6}{|l|}{$\begin{array}{l}\text { Страноязыковая принадлежность } \\
\text { респондента }\end{array}$} \\
\hline русскоязычные в Латвии & - & 0,039 & $-0,068 * *$ & $-0,153 * *$ & 0,035 \\
\hline русскоязычные в Эстонии & $-0,039$ & - & $-0,106 * *$ & $-0,190 * *$ & $-0,004$ \\
\hline латыши & $0,088 * *$ & $0,138 * *$ & - & $-0,109 * *$ & $0,133 * *$ \\
\hline эстонцы & $0,206^{* *}$ & $0,259 * *$ & $0,114 * *$ & - & $0,254 * *$ \\
\hline россияне & $-0,051$ & 0,005 & $-0,148 * *$ & $-0,270 * *$ & - \\
\hline \multicolumn{6}{|c|}{ Контрольные независимые переменные } \\
\hline Возраст & & & $-0,283 * *$ & & \\
\hline Пол женский & & & 0,006 & & \\
\hline Образование высшее & & & $-0,002$ & & \\
\hline $\begin{array}{l}\text { Состоит в зарегистрированном браке и } \\
\text { живет вместе с супругом/супругой }\end{array}$ & & & $-0,084 * *$ & & \\
\hline Количество детей у респондента & & & $-0,037 *$ & & \\
\hline \multicolumn{6}{|l|}{$\begin{array}{l}\text { Размер населенного пункта (референтная } \\
\text { категория - меньше } 5 \text { тыс. человек) }\end{array}$} \\
\hline от 5 до 20 тыс. & & & 0,019 & & \\
\hline от 20 до 100 тыс. & & & $0,041 *$ & & \\
\hline от 100 до 500 тыс. & & & $-0,037$ & & \\
\hline свыше 500 тыс. & & & 0,029 & & \\
\hline Респондент иммигрант & & & $-0,015$ & & \\
\hline Отец иммигрант & & & $-0,039$ & & \\
\hline Мать иммигрантка & & & 0,028 & & \\
\hline \multicolumn{6}{|l|}{$\begin{array}{l}\text { Среднемесячный доход домохозяйства } \\
\text { (референтная категория - низкий) }\end{array}$} \\
\hline средний & & & $-0,025$ & & \\
\hline высокий & & & 0,017 & & \\
\hline$R^{2}, \%$ & & & 16,3 & & \\
\hline
\end{tabular}

Примечание: *-значимо на уровне 0,05, **-значимо на уровне 0,001. 
На рисунке 9 отображены оценки фактора традиционности-модерности в пяти рассматриваемых страноязыковых группах, предсказанные на основе регрессионных моделей, при этом влияние со стороны социально-демографических переменных как бы выносилось за скобку.

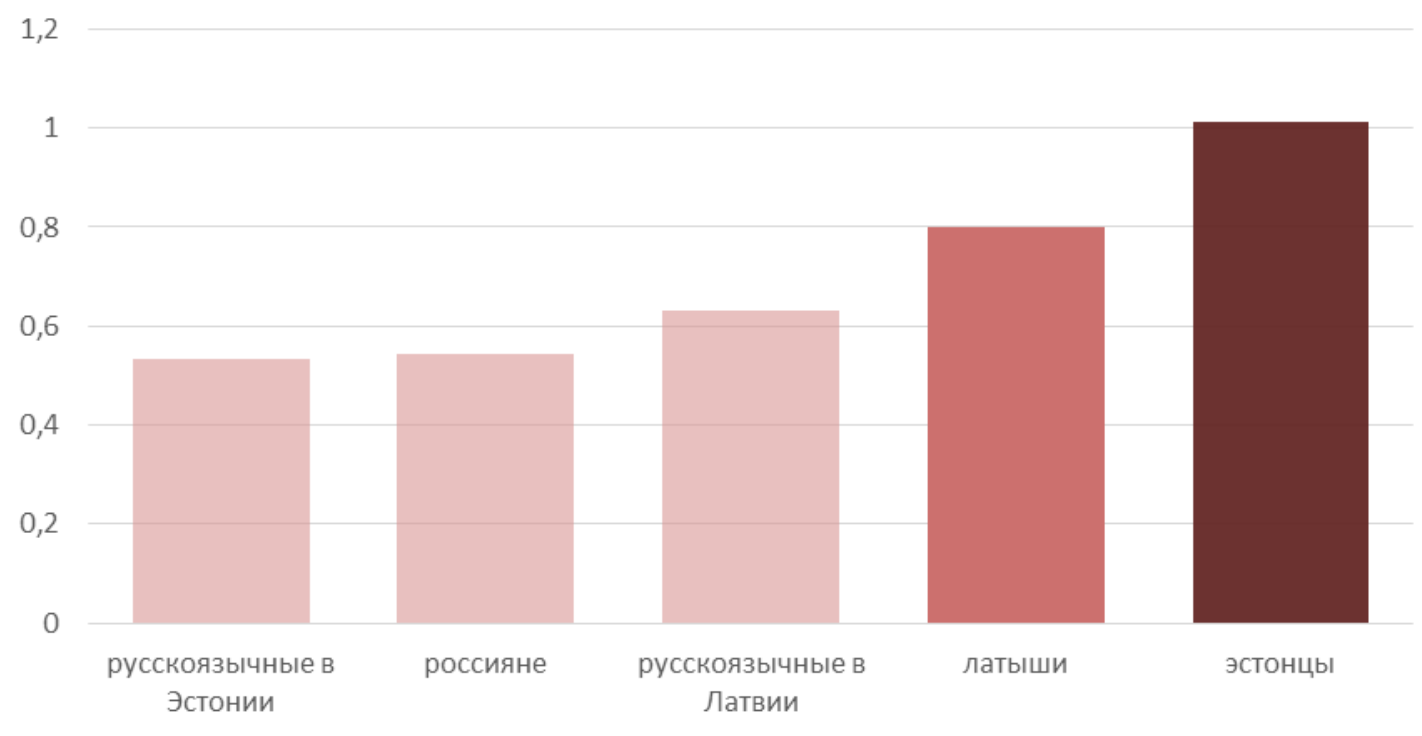

Рисунок 9. Средние оценки общего фактора традиционности - модерности в пяти страноязыковых группах, предсказанные на основе регрессионных моделей (влияния социально-демографических контрольных переменных вынесены за скобку; группы, статистически значимо различающиеся по средним оценкам, обозначены разными цветовыми оттенками)

Таким образом, на рисунке 9 средние значения очищены от влияния социальнодемографических переменных, и этим они отличаются от средних значений фактора, фигурирующих на рисунке 8. Кроме различий между русскоязычными в Эстонии, русскоязычными в Латвии и россиянами, все остальные различия являются статистически значимыми (в основном при $p<0,001$ ). Это значит, что русскоязычные Эстонии и Латвии вместе с россиянами придерживаются наиболее традиционных семейно-гендерных взглядов, латыши - несколько более модерных и, наконец, эстонцы являются носителями наиболее модерных представлений. Таким образом, благодаря контролю социальнодемографических переменных, соотношение средних несколько изменилось в сравнении с тем, что мы наблюдали при сравнении «сырых» значений фактора (рисунок 9). Теперь можно утверждать, что по показателю традиционности-модерности взглядов все три русскоязычные группы - россияне, а также русскоязычные в Эстонии и Латвии примерно одинаковы (не имеют значимых различий).

\section{ВЫВОДЫ}

Исследование подтвердило роль русскоязычности в детерминации традиционностимодерности нормативных взглядов на семью и гендер. Мы предполагали, что в силу культурной привязанности к России русскоязычное население Латвии и Эстонии по 
степени традиционности-модерности своих нормативных взглядов в семейно-гендерной сфере занимает промежуточное положение между более модерно настроенными латышами и эстонцами, с одной стороны, и более традиционно настроенными россиянами - с другой. Это предположение подтвердилось только частично. Русскоязычное население Латвии и Эстонии, действительно, придерживается более традиционных взглядов, чем латыши и эстонцы, но от россиян по своим семейно-гендерным взглядам значимо не отличается.

Таким образом, по обобщенной шкале традиционности-модерности страноязыковые группы расположились в таком порядке: более традиционалистские нормативные взгляды на семью и гендер разделяют живущие в Эстонии и Латвии русскоязычные, а также жители России, а далее, если двигаться в направлении меньшей традиционности и большей модерности, на этой шкале располагаются латыши, наибольшая модерность характерна для эстонцев.

Можно предположить, что внутристрановая дифференциация взглядов на семью и гендер между русскоязычными жителями Латвии и Эстонии и живущими с ними в одной стране латышами или эстонцами возникает под действием механизмов, которые связаны с упомянутыми ранее особенностями идентичности русскоязычных жителей этих стран. Для них характерна двойственная (hyphenated) [Çaglar 1997] идентичность, в которой присутствует и сознание принадлежности к своей стране (Латвии или Эстонии), и одновременно сознание принадлежности к носителям русского языка и русской культуры, для которых референтной группой, трендсеттером, служит Россия. Эта референтная группа - более традиционалистская, чем большинство европейских стран [Магун 2009; Фабрикант, Магун 2014], поэтому ориентация на нее ведет к движению русскоязычного населения Латвии и Эстонии в сторону большего традиционализма и меньшей модерности.

На взгляды русскоязычных жителей Эстонии и Латвии, по-видимому, прямо влияют и взгляды более модерно ориентированных жителей собственной страны, латышей или эстонцев, и взгляды жителей других европейских стран, а также соответствующие социальные нормы. Но, судя по полученным результатам, эти прямые влияния оказываются сравнительно слабыми.

Стоит учитывать, что влияние со стороны более модерно ориентированной части населения может иметь и иной, обратный эффект. Русскоязычная идентичность может выполнять в данном случае своеобразную защитную, блокирующую функцию в отношении более модерных взглядов. В Эстонии и Латвии может действовать механизм, описанный А. Торнтон и Л. Янг-ДеМарко [Thornton, Young-DeMarco 2001] применительно к США, где бурное распространение среди американцев в 1960-1980-х годах прошлого века новых семейных норм и практик вызвало в качестве реакции усиление и противоположного по смыслу типа нормативного сознания, т.е. укрепление и рост популярности традиционалистских взглядов на семейные отношения. Этот феномен можно было бы назвать реактивным контрастом: традиционалистские взгляды радикализируются через самоопределение их носителей как противостоящих инновационно настроенному большинству.

В каких случаях более модерно ориентированная часть населения страны оказывает модернизирующее влияние на категорию населения, придерживающуюся более 
традиционных взглядов («эффект ассимиляции»), а когда, наоборот, возникает эффект отталкивания и население с традиционными взглядами еще более в них укрепляется («эффект контраста») - вопрос для дальнейших исследований.

Анализируя эффекты социально-демографических переменных на традиционностьмодерность нормативных взглядов, мы установили отсутствие значимых различий между иммигрантами (в первом и втором поколениях) и неиммигрантами. Это подтверждает внутреннее, а не внешнее, происхождение различий между русскоязычными и нерусскоязычными: имеющийся у части русскоязычных респондентов опыт первичной социализации в России, принесенный в страну проживания, не сказывается на их нормативных взглядах. На них преимущественно влияет актуальный опыт жизни в Латвии и Эстонии и то, как современная Россия видится русскоязычным из этих стран.

\section{БЛАГОДАРНОСТИ}

Авторы благодарят М.С. Тольца, двух анонимных рецензентов, а также всех участников семинара "Behavior patterns of immigrant Russians in comparison to origin and destination countries", проходившего в рамках 10-й ежегодной конференции эстонских социальных наук (Таллинн, 2016), за ценные замечания.

\section{ЛИТЕРАТУРА}

Вишневский А.Г. (2010). Серп и рубль. Консервативная модернизация в СССР. М.: Изд. дом Высшей школы экономики. 430 с.

Вишневский А.Г. (2011). Цивилизация, культура и демография // Общественные науки и современность. 2: 57-76.

Вишневский А.Г., С.В. Захаров, Е.И. Иванова (2006). Обновление семьи и брака // Демографическая модернизация России 1900-2000 / Под ред. А. Вишневского. М.: Новое издательство: 66-146.

Инглхарт Р. (2018). Культурная эволюция. Как изменяются человеческие мотивации и как это меняет мир. М.: Мысль. 334 с.

Магун В.С. (2009). Нормативные взгляды на семью у россиян и французов: традиционное и современное // Родители и дети, мужчины и женщины в семье и обществе / Под ред. С.В. Захарова, Т.М. Малевой, О.В. Синявской. М.: НИСП: 477-516.

Руднев М.Г. (2009). Влияние «русскоязычности» на жизненные ценности // Социология: методология, методы и математическое моделирование (Социология: 4М). 28: 107-128.

Сакевич В.И. (2014). Отношение к разводам, внебрачным отношениям, гомосексуализму, абортам, контрацепции в 40 странах мира // Демоскоп Weekly. 595-596. URL: http://demoscope.ru/weekly/2014/0595/reprod01.php (дата обращения: 08.05.2018).

Фабрикант М.С., В.С. Магун. (2014). Семейные ценности россиян и европейцев // Демоскоп Weekly. 613-614: 6-19 (дата обращения: 12.06.2018). 
Borinskaya S., R. Inglehart, J. Harro, A. Cotter, E. Ponarin, C. Welzel. (2014). Genetic factors, cultural predispositions, happiness and gender equality // Journal of Research in Gender Studies. 4(1): 32-100.

Çaglar A. (1997). Hyphenated identities and the limits of culture // The politics of multiculturalism in the New Europe / T. Modood, P. Werbner, eds. London: Zed Books: 169185.

Cheskin A. (2015). Identity and integration of Russian speakers in the Baltic States: A framework for analysis // Ethnopolitics. 14(1): 72-93.

Ehin P. (2016). Identity and foreign policy: Baltic-Russian relations and European integration. London: Routledge. 216 p.

Freedman E. (2007). No turning back: The history of feminism and the future of women. NYC: Ballantine Books. 464 p.

Gill R. (2007). Postfeminist media culture Elements of a sensibility // European journal of cultural studies. 10(2): 147-166.

Ivlevs A. (2013). Minorities on the move? Assessing post-enlargement emigration intentions of Latvia's Russian speaking minority // The Annals of Regional Science. 51(1): 33-52.

Kostenko V., P. Kuzmichev, E. Ponarin (2016). Attitudes towards gender equality and perception of democracy in the Arab World // Democratization. 23(5): 862-891.

Latvia Population 2018 (2018). World Population Review. URL:

http://worldpopulationreview.com/countries/latvia-population (дата обращения: 01.06.2018).

Lesthaeghe R. (1995). The second demographic transition in Western countries: An interpretation // Gender and family change in industrialized countries. 17-62.

Population by ethnic nationality, 1 January, years (2017). Statistics Estonia: Tallinn. URL: http://www.stat.ee/34278 (дата обращения: 01.06.2018).

Rivera L.A., A. Tilcsik (2016). Class advantage, commitment penalty: The gendered effect of social class signals in an elite labor market // American Sociological Review. 81(6): 10971131.

Thornton A., L. Young-DeMarco (2001). Four decades of trends in attitudes toward family issues in the United States: The 1960s through the 1990s // Journal of marriage and family. 63(4): 1009-1037.

Vihalemm T., A. Masso (2003). Identity dynamics of Russian-speakers of Estonia in the transition period // Journal of Baltic Studies. 34(1): 92-116. 


\title{
NORMATIVE ATTITUDES TO FAMILY AND GENDER: RUSSIAN-SPEAKERS IN LATVIA AND ESTONIA IN A COMPARATIVE PERSPECTIVE (BASED ON THE 2018 SURVEYS)
}

\author{
MARHARYTA FABRYKANT, VLADIMIR MAGUN
}

\begin{abstract}
The article presents the results of a comparative study of the level of traditionality/modernity of normative gender attitudes in the Russian-speaking population of Latvia and Estonia. The research hypothesis is that Russian-speakers hold an intermediate position between the relatively more traditional Russians and the relatively more modern non-Russian-speaking populations of Latvia and Estonia. To test the hypothesis, we used survey data of the 2008 wave of the European Values Study including seven indicators of family and gender attitudes. The results obtained proved Russian-speakers in Latvia and Estonia to hold more traditional views compared to the non-Russian-speaking population of these countries. At the same time, Russian-speakers in Latvia, as hypothesized, appeared to be more modern in their views than Russians. Russian-speakers in Estonia, however, were found to be similar to Russians in their views and much more traditional than Russian-speakers in Latvia, while non-Russian-speakers in Estonia, on the contrary, presented more modern views than their counterparts in Latvia. The results obtained confirm the theoretical proposition that social identity may affect even normative attitudes substantively unrelated to the criteria on which this identity is based and that this impact is mediated by the general level of traditionality/modernity ascribed to a culture by its representatives as actual and/or desirable. No differences in the power and direction of influence of sociodemographic variables were found across samples: in all the five groups, more traditional views are espoused primarily by older respondents and those legally married. At the same time, education and income levels were found to have no significant impact, and no significant differences between men and women and between first and second generation immigrants vs. not immigrants were discovered.
\end{abstract}

Key words: modernization, social norms, gender, family, Russia, Baltics.

\begin{abstract}
MARHARYTA FABRYKANT (mfabrykant@ hse.ru), NATIONAL RESEARCH UNIVERSITY HighER SCHOOL OF ECONOMICS, RUSSIA.

VLAdimir MAgun (maghome@yandex.ru), Institute of Sociology of FCTAS RAS, Russia; NATIONAL RESEARCH UNIVERSITY HIGHER SCHOOL OF ECONOMICS, RUSSIA.
\end{abstract}

DATE RECEIVED : JULY 2018.

\section{REFERENCES}

Borinskaya S., R. Inglehart, J. Harro, A. Cotter, E. Ponarin, C. Welzel. (2014). Genetic factors, cultural predispositions, happiness and gender equality // Journal of Research in Gender Studies. 4(1): 32-100.

Çaglar A. (1997). Hyphenated identities and the limits of culture // The politics of multiculturalism in the New Europe / T. Modood, P. Werbner, eds. London: Zed Books: 169185.

Cheskin A. (2015). Identity and integration of Russian speakers in the Baltic States: A framework for analysis // Ethnopolitics. 14(1): 72-93.

Ehin P. (2016). Identity and foreign policy: Baltic-Russian relations and European integration. London: Routledge. 216 p. 
Fabrykant M.S., V.S. Magun. (2014). Semeynye tsennosti rossiyan i evropeytsev [Family values in Russians and Europeans] // Demoskop Weekly [Demoscope Weekly].613-614: 6-19. URL: http://www.demoscope.ru/weekly/2014/0613/demoscope613.pdf (accessed: 12.06.2018).

Freedman E. (2007). No turning back: The history of feminism and the future of women. NYC: Ballantine Books. 464 p.

Gill R. (2007). Postfeminist media culture Elements of a sensibility // European journal of cultural studies. 10(2): 147-166.

Inglehart R. (2018). Kul'turnaya evolyutsiya. Kak izmenyayutsya chelovecheskie motivatsii i kak eto menyaet mir [Cultural evolution. People's motivations are changing, and reshaping the world]. Moscow: Mysl'. 334 p.

Ivlevs A. (2013). Minorities on the move? Assessing post-enlargement emigration intentions of Latvia's Russian speaking minority // The Annals of Regional Science. 51(1): 33-52.

Kostenko V., P. Kuzmichev, E. Ponarin (2016). Attitudes towards gender equality and perception of democracy in the Arab World // Democratization. 23(5): 862-891.

Latvia Population 2018 (2018). World Population Review. URL: http://worldpopulationreview.com/countries/latvia-population (accessed: 01.06.2018).

Lesthaeghe R. (1995). The second demographic transition in Western countries: An interpretation // Gender and family change in industrialized countries. 17-62.

Magun V.S. (2009). Normativnye vzglyady na sem'yu u rossiyan i frantsuzov: traditsionnoe i sovremennoe [Normative views on family in Russians and the French: traditional and modern] // Roditeli i deti, muzhchiny i zhenshhiny v sem'e i obshhestve [Parents and children, men and women in family and society] / S.V. Zaharov, T.M. Maleva, O.V. Sinyavskaya, eds. Moscow: NISP: 477-516.

Population by ethnic nationality, 1 January, years (2017). Statistics Estonia: Tallinn. URL: http://www.stat.ee/34278 (accessed: 01.06.2018).

Rivera L.A., A. Tilcsik (2016). Class advantage, commitment penalty: The gendered effect of social class signals in an elite labor market // American Sociological Review. 81(6): 10971131.

Rudnev M.G. (2009). Vliyanie «russkoyazychnosti» na zhiznennye tsennosti [Impact of Russianspeaking on basic values]. // Sotsiologiya: metodologiya, metody i matematicheskoe modelirovanie (Sotsiologiya: 4M) [Sociology: methodology, methonds and mathematical modeling (Sociology: 4M)]. 28: 107-128.

Sakevich V.I. (2014). Otnoshenie k razvodam, vnebrachnym otnosheniyam, gomoseksualizmu, abortam, kontratseptsii v 40 stranakh mira [Attitudes towards divorce, extramarital rrelations, homosezuality, abortions, and contraception in 40 countries] // Demoskop Weekly [Demoskope Weekly]. 595-596. URL: http://demoscope.ru/weekly/2014/0595/reprod01.php (accessed: 08.05.2018).

Thornton A., L. Young-DeMarco (2001). Four decades of trends in attitudes toward family issues in the United States: The 1960s through the 1990s // Journal of marriage and family. 63(4): 1009-1037.

Vihalemm T., A. Masso (2003). Identity dynamics of Russian-speakers of Estonia in the transition period // Journal of Baltic Studies. 34(1): 92-116. 
Vishnevsky A.G. (2010). Serp i rubl'. Konservativnaya modernizatsiya v SSSR [Sickle and Rouble. Conservative modernization in the USSR] Moscow: Izd. dom Vysshey shkoly ekonomiki. $430 \mathrm{p}$.

Vishnevsky A.G. (2011). Tsivilizatsiya, kul'tura i demografiya [Civilization, culture and demography] // Obshhestvennye nauki i sovremennost' [Social sciences and modernity]. 2: 57-76.

Vishnevsky A.G., S.V. Zakharov, E.I. Ivanova (2006). Obnovlenie sem'i i braka [Rejuvenation of family and marriage] // Demograficheskaja modernizacija Rossii 1900-2000 [Russia's demographic modernization, 1900-2000] / A. Vishnevsky, ed. Moscow: Novoe izd-vo: 66146. 